\title{
Ergenlerin Sahip Olduğu Gelecek Beklentisi, Umut ve Psikolojik İyi Oluş Arasındaki Yordayıcı İlişkiler
}

\author{
Sema ÇALIŞKAN ${ }^{1}$ (iD), Bülent DİLMAÇ ${ }^{2}$ (iD \\ ${ }^{1}$ Milli Eğitim Bakanlı̆̆l, Konya, Türkiye,semadag197@gmail.com \\ ${ }^{2}$ Necmettin Erbakan Üniversitesi, Konya,Türkiye, bulentdilmac@gmail.com
}

\begin{tabular}{|c|c|}
\hline Makale Bilgileri & ÖZ \\
\hline $\begin{array}{l}\text { Makale Geçmişi } \\
\text { Geliş: } 12.11 .2021 \\
\text { Kabul: } 24.12 .2021 \\
\text { Yayın: } 31.12 .2021 \\
\text { Anahtar Kelimeler: } \\
\text { Gelecek Beklentisi } \\
\text { Psikolojik İyi Oluş } \\
\text { Umut }\end{array}$ & $\begin{array}{l}\text { Bu araştırma ergenlerin gelecek beklentisi, umut ve psikolojik iyi oluş düzeyleri arassındaki yordayıcı } \\
\text { ilişkileri ortaya koymak amacıyla gerçekleştirilmiştir. Araştırmanın çalışma grubunu 2019-2020 eğitim- } \\
\text { öğretim yılında Türkiye'nin çeşitli özel ve devlet liselerinde öğrenim görmekte olan } 214 \text { (\%49.3) erkek, } \\
208 \text { (\%50.7) kız öğrenci olmak üzere toplam } 422 \text { öğrenci oluşturmaktadır. Çalışmada veri toplama araçları } \\
\text { olarak; Psikolojik İyi Oluş Ölçeği, Ergen Gelecek Beklentileri Ölçeği, Sürekli Umut Ölçeği kullanılmıştır. } \\
\text { Aynı zamanda katılımcıların demografik özelliklerinin belirlemesi amaciyla kişisel bilgi formu } \\
\text { kullanılmıştır. Elde edilen verilerin analizinde yapısal eşitlik modeli kullanılmıştır. Araştırma bulgularına } \\
\text { göre gelecek beklentisi ile umut değişkeni arasında pozitif yönde anlamlı bir ilişki olduğu görülmüştür. Bu } \\
\text { bağlamda ergenlerin geleceğe dair beklentileri arttıkça umut düzeyleri de artacaktır. Diğer yandan ergen } \\
\text { gelecek beklentisi ile psikolojik iyi oluş değişkeni arasında pozitif yönde anlamlı ilişki olduğu } \\
\text { görülmüşsür. Başka bir ifadeyle ergenlerin gelecek beklentileri arttıkça psikolojik iyi oluş düzeyleri de } \\
\text { artacaktır. Ergenlerin umutları ile psikolojik iyi oluş düzeyleri arasında da pozitif yönde anlaml ilişki } \\
\text { olduğu görülmüştür. Bu çerçevede ergen bireylerin umutları arttıkça psikolojik iyi oluş düzeylerinin de } \\
\text { arttığı ortaya çımıştır. İçsel motivasyon kaynaklarını keşfederek geleceğe dair beklentilerini oluşturan } \\
\text { ergenlerin, bu planlarının gerçekleşeceğine dair daha umut dolu oldukları görülmüştür. Gelecekten olumlu } \\
\text { beklentiler içerisinde olan ve bu sayede yüksek umut düzeyine sahip ergenlerin ruh sağlığı ve psikolojik iyi } \\
\text { oluş düzeyleri de pozitif yönde etkilenmektedir. Olumlu gelecek beklentisine sahip ergenlerin yaşamı daha } \\
\text { anlamlı buldukları, iç kontrolü sağlayarak kararlarını alabildikleri ve kişiler arasi ilişkilerde daha sicak } \\
\text { oldukları görülmüstür. }\end{array}$ \\
\hline
\end{tabular}

\section{Predictive Relationships Between Adolescents'Future Expectation, Hope and Psychological Well-Being}

\begin{tabular}{|c|c|}
\hline Article Info & ABSTRACT \\
\hline $\begin{array}{l}\text { Article History } \\
\text { Received: } 12.11 .2021 \\
\text { Accepted: } 24.12 .2021 \\
\text { Published: } 31.12 .2021 \\
\text { Keywords: } \\
\text { Future Expaction, } \\
\text { Psychological well-being, } \\
\text { Hope }\end{array}$ & $\begin{array}{l}\text { This research aims to reveal the predictive relationships between expectation, hope, and psychological well-being levels } \\
\text { of adolescents. The sample included total of } 422 \text { students from } 2019-2020 \text { academic year; } 214 \text { ( } 49.3 \%) \text { male and } 208 \\
(50.7 \%) \text { female studying in various state and private high schools in Turkey. Psychological Well-Being Scale, } \\
\text { Adolescent Future Expectations Scale, Continuous Hope Scale the demographic questionmnaire tools were utilized. At } \\
\text { the same time, a personal information form was used to determine the demographic characteristics of the participants. } \\
\text { The structural equation model was adopted to analyse the obtained data. Based on research findings, it is considered that } \\
\text { there is a significant positive relationship between future expectation and the hope variable. In this context, as the future } \\
\text { expectations of teenagers increase, so will their hope. In addition, it is also observed that there was a significant positive } \\
\text {, relationship between the adolescents future expectance and psychological well-being variable. In other words, } \\
\text { adolescents'psychological well-being improves in accordance with their expectations of future. It is also understood that } \\
\text { this relationship can also be applied to hopes and psychological well-being levels of adolescents. In this context, it } \\
\text { emerged that the hopes of adolescents and their psychological well-being were in positive correlation. It was observed } \\
\text { that adolescents who are forming for their future expectations by discovering their internal motivation resources were } \\
\text { more hopeful that these plans will come real. The psychological health and well-being levels of adolescents with } \\
\text { optimistic expectations as well as high hopes for the future, are also positively affected. It is also observed that teenagers } \\
\text { with optimistic future expectations are more likely to find life more meaningful, able to take better decisions by internal } \\
\text { control and are warmer in interpersonal relationships. }\end{array}$ \\
\hline
\end{tabular}




\section{GíRiş}

Kimliğimizi geliştirdiğimiz, sonraki dönemler içerisinde bizi biz yapan pek çok özelliğimizi oluşturacağımız ergenlik dönemi gelişim evrelerimiz içerisinde kritik öneme sahip dönemlerden birisidir. Erikson'a (1968) göre ergenlik, kimlik bunalımlarıyla beraber gelecek planlamasının ortaya çıktığı bedensel, bilişsel, toplumsal ve ahlaki açıdan çeşitli değişikliklerin yaşandığı önemli bir gelişimsel görevdir. Kimliklerini oluşturdukları bu dönem içerisinde ergen bireylerin anne-baba ilişkileri yeni bir şekle dönüşür, yaşıtlarıyla ilişkileri farklılaşır, biyolojik değişiklikler ile beden imgesine olan ilgi artar (Santrock,2012). Genç bireyler yalnızca beden değişimleri, anne-baba ilişkileri ile değil aynı zamanda kimlik oluşturma, geleceklerine yönelik karar verme, amaçlar oluşturma gibi pek çok faktörle de ilgilenmektedirler. Bu dönemde bireylerin birden fazla alanda sorumluluk alması beklenir. Bu sorumluluklara önceki gelişim dönemlerinden gelen akademik başarı, aktivitelere katılımın yanı sıra yakın arkadaşlıklar kurmak ve uyumlu bir kimlik geliştirmek gibi yeni görevlerde eklenmiştir (Masten \& Coatsworth,1998).

Ergenlik dönemi içerisinde eğitimlerini sürdüren bireyler, üst eğitim kurumuna devam etme, mesleğe yönelme, toplum tarafından belirlenen rollere uyum sağlama gibi pek çok gelişimin göreviyle birlikte gelecek hedeflerini belirleyecek adımlar atması bu dönemde gelecek beklentisi kavramını daha da önemli hale getirmektedir (Türkon, 2019) İçinde bulundukları çalkantılı firtına döneminde (Hall,1904, Akt. Santrock, 2012) ergenlerin gelecek zamana dönük oluşturdukları beklentiler; örneğin meslek seçimi konusundaki ve yaşam biçimi konusundaki beklentileri, yetişkin yaşantılarına etki etmekte, buna bağlı olarak da benlik ve kimlik oluşumları şekillenmektedir (Artar, 2003). Bu bağlamda gelecek beklentisinin bireyle ilişkili terimlerle kavramsallaştırılması gereken çok aşamalı, karmaşık ve uzun bir süreç olduğunu vurgulamak gerekmektedir (Nurmi, 1991).

Gelecek beklentisi kavramına teorik açıdan bakıldığında bireylerin geçmiş yaşamlarındaki tecrübeleri bağlı olarak ortaya çıkardıkları ve kendileri ile ilgili oluşturdukları algılar olarak tanımlandığı görülmektedir (Rotter, 1975). Bu temelde de gelecek yöneliminin motivasyon, planlama ve değerlendirme olarak üç temel kavram üzerinden incelendiği görülmüştür (Nurmi, 1991). Gelecek beklentisini şekillendirirken bireylerin öncelikle yaşamdan beklentileri, ilgileri, değerleri gibi unsurları göz önüne alması beklenir. Zira motivasyon kaynaklarını keşfetmiş, değerlerinin farkında olan bireyler geleceğe ilişkin hedeflerini daha belirgin hale getirebilirler. Belirginleştirilmiş hedeflerin ardından bu hedeflere nasıl ulaşılacağına dair planlama yapmak, karşılaşılan sorunlarda problem çözme becerilerini harekete geçirmek de önemli görülmektedir (Nurmi,1991). Bireyin kendi beklentilerinin, ilgilerinin yanı sıra gelecek beklentisi üzerinde etkili olan olumlu ya da olumsuz olduğu düşünülen pek çok değişken bulunduğu görülmektedir. Özellikle gelecek beklentisinin çok boyutlu yapısı düşünüldüğünde bireyin bilişsel, (Nurmi, 1991), sosyal-kültürel, ekonomik (Seginer, 2003; Roberts \& Bengston, 1993) bileşenlerden etkilenmesi de olası görünmektedir. Nitekim ergenlik dönemi içerisinde görülen hayali seyirci kavramından hareketle; aslında genç bireylerin ebeveynlerinin tutum (Johnson vd. 2014) ve akranları gibi sosyal yapının da düşünce ve beklentilerinden etkilendiği de ortaya çıkmaktadır (Nurmi,1991; Givyin, 2001 ). Yetiştikleri sosyal kültür çevresi (Iovu vd. 2008), aile yapıs1 (McCabe \& Barnet, 2000), bu ailenin sosyo-ekonomik durumu da genç bireylerin geleceğe dair beklentilerini oluşturmalarına etki eden faktörler arasındadır.

Ergenlerin gelecek zamana dönük pek çok bileşenin etkisiyle de oluşturdukları beklentiler ve bu beklentilerin gerçekleşeceğine, yaşanan olaylarda çıkış yolu bulunacağına dair inanç olgusu da önemli görülmektedir. Dolayısıyla bireyin amaçlarını belirlemesi, amaçlarını harekete geçirme güdüsü ve bu amaçlara ulaşma yollarını düşünmesi olarak tanımlanan kavram umuttur (Snyder, 2000). Geleceğe yönelik olumlu beklentilere sahip olma duygusunu belirten umut, insanın gelecekte karşılaşabileceği olumsuz yaşantılarla baş edebileceği duygusunu oluşturarak ruh sağlığını olumlu etkilemektedir (Sürücü \& Mutlu, 
2016). Buradan hareketle gelecek beklentisi ile umut arasında ilişki görülmesi olasıdır.

Snyder tarafından geliştirilen umut teorisi, hedeflerin önemini vurgulayan bir yapı üzerine inşa edilmiştir. Bireylerin kendi değerleri ile uyumlu hedefler seçmesi önemli bir unsurdur (Snyder, 1995). Umut, bireyin belirlediği hedefine doğru sürekli çaba göstermesini sağlar. Yüksek umutlu insanlar, hedeflerine meydan okur gibi görünürler ve yüksek hedefler onların gözlerini korkutmaz, heyecan verici ve motive edici zorluklar olarak görürler. Yüksek umuda sahip bireyler hedeflerine giden yolda ilerlemek için yüksek motivasyon ve enerjiye sahiptirler. Bu bireylerin rahatsız edici ve stresli koşullarda bile, umut düzeyleri düşük bireylere göre çabalarını sürdüreceklerine dair kanıtlar vardır (Snyder, 2002). Diğer yandan yüksek düzeyde bir umut düzeyi stresli yaşam olaylarında ergen bireylere psikolojik bir güç olarak destek sağlayacaktır (Valle vd. 2006).

Umut kavramının yanı sıra ergenlik döneminin sağlıklı bir şekilde atlatılmasında bireyin psikolojik iyi oluş düzeyi de önemli hale gelmektedir (Çelik, 2015). Psikolojik iyi oluş kavramı zorluklar karşılaşıldığında bireyin potansiyellerini harekete geçirmesi ve anlamlı bir yaşam için kendini gerçekleştirmesini içerir (Ryff \& Singer, 2008). Ryff' in (1989) ortaya koyduğu "Psikolojik iyi oluş modeli" temelde altı boyuttan oluşmaktadır. Bu boyutlardan kendini kabul, bireyin geçmiş yaşamına veya kendisine ilişkin olumlu değerlendirmelerini; kişisel gelişim, bir birey olarak devamlı büyüdüğü ve geliştiği duygusunu; yaşam amacı, bireyin yaşamının anlamlı ve amaçlı olduğuna dair inancını; diğerleriyle olumlu ilişkiler, kişilerarası ilişkilerde sıcaklık ve güveni; çevresel egemenlik, bireyin kendi istek ve ihtiyaçları doğrultusunda çevresindeki yaşamı etkili bir şekilde yönlendirebilme kapasitesini ve özerklik, kendi kendine karar verme duygusunu içermektedir (Ryff, 1989; Ryff, 2013; Ryff \& Singer, 2008). Psikolojik iyi oluş kuramı ortaya konduktan sonra temellenmeleri üzerine yapılan çalışmalarda psikolojik iyi oluşun temelinde ergenlik dönemindeki yaşantıların çok fazla etkisi olabileceği görülmüştür (Gülaçt1, 2009).

Bireylerin gelecek beklentilerini planlama süreçlerini de göz önüne aldığımızda, geleceğe dair yönelimleri olumlu olan ergenlerin kendi değerlerinin ve içsel motivasyon kaynaklarının farkında olması önem kazanmaktadır. Böylece gençlerin geleceğe ilişkin beklentileri ve bu beklentilerin gerçekleşmesine yönelik umutları hem onların ruh sağlığını ve psikolojik iyi oluş düzeylerini hem de toplumun değişim yönünü etkilediği de düşünülebilir. Zira ergenlerde gelecek beklentisinin yüksek olması birçok açıdan önem arz ettiği gibi ergenin iç kontrol odağ azaltabilmesine ve çevresiyle kurduğu sosyo-duygusal ilişkilerinde ilerlemesine de katkı sağlamaktadır (Catalano vd. 2004).

$\mathrm{Bu}$ bağlamda kişilik gelişiminin çeşitli boyutlarında önemli değişimler yaşanan ergenlik dönemindeki bireyler gelecekteki amaçlarını belirlemek, bu amaçlara ulaşmak için umutla çaba göstermesi önemli görülmektedir. $\mathrm{Bu}$ nedenle psikolojik iyi oluş, umut düzeylerinin özellikle yaşamın önemli bir aşaması ergenlik dönemindeki lise öğrencilerinde saptanması iyi oluş düzeylerini yükseltmeye yönelik çabaları daha etkili hale getirecektir. Diğer yandan olumsuz gelecek beklentisine sahip bireylerin içinde bulundukları durumlar değerlendirildiğinde, ergenlik dönemindeki bireylerde gelecek beklentisi ile ilişkisi bulunan faktörlerin belirlenmesi ve ardından bu faktörlere yönelik çalışmaların yürütülmesi önemli görülmektedir. Buradan hareketle araştırmanın genel amacı ergenlerin gelecek beklentisi, umut ve psikolojik iyi oluş düzeyleri arasındaki yordayıcı ilişkileri ortaya koymaktır. Bu genel amaç çerçevesinde alt amaçlar aşağıdaki şekilde belirlenmiştir.

1.Ergenlerin sahip oldukları gelecek beklentisi umut düzeyini yordamakta mıdır?

2.Ergenlerin sahip oldukları gelecek beklentisi psikolojik iyi oluş düzeyini yordamakta mıdır?

3.Ergenlerin umut düzeyi psikolojik iyi oluş düzeyini yordamakta mıdır? 


\section{YÖNTEM (METHOD)}

\section{Araştırma Modeli}

Nicel araştırma paradigmasıyla yapılan bu çalışmada, ergenlerin sahip olduğu gelecek beklentisi, umut ve psikolojik iyi oluş düzeyi arasındaki yordayıcı ilişkilerin belirlenmesi ve bu değişkenlerinin ilişkilerinin yapısal eşitlik modeli ile sınanması amaçlanmıştır. Bu amaca yönelik araştırma, genel tarama modelinin alt boyutlarından olan ilişkisel tarama modeline göre yapılmıştır.

Bir konuya ilişkin çok sayıda katılımcının oluşturduğu bir evrende, evrenin tamamı ya da evrene ait bir grup örneklem üzerinden, evren hakkında genel bir yargıya ulaşılması amacıyla yapılan tarama araştırmaları, genel tarama modelleri olarak adlandırılmaktadır. Genel tarama modelleri, tekil veya ilişkisel taramalar yapma imkânı sağlamaktadır (Karasar, 2015). Bu tarama modellerinden ilişkisel tarama modeli, iki ya da daha fazla sayıda değişkenin arasındaki ilişkinin, değişkenlere herhangi bir müdahale yapılmadan incelendiği araştırma modelleridir (Büyüköztürk, Çakmak, Akgün, Karadeniz, Demirel; 2018).

\section{Örneklem/Çalışma Grubu/Katılımcılar}

Araştırmanın çalışma grubunu 2019-2020 eğitim-öğretim yılında Türkiye’nin özel ve devlet okullarının Fen, Anadolu ve Meslek liselerinin 9.10.11.12. sınıflarında öğrenim görmekte olan öğrenciler oluşturmaktadır. Araştırma çalışma grubu 14 yaş ile 18 yaş arası öğrencilerden oluşmaktadır. Uygulama öncesi katılımcılar, araştırmanın amac1 ile ölçeğin nasıl uygulanacağı konularında bilgilendirilmiştir. Ölçeklerin uygulanmasında gönüllülük ilkesi esas alınmıştır. Toplamda 482'yi bulan veri sayısı, geçersiz sayılan verilerden dolayı (eksik işaretleme, yarım bırakma, soruları anlayamama... vb.) 422' ye düşmüştür. 112 öğrenci 9.sınıf, 113 öğrenci 10.sınıf, 166 öğrenci 11.sınıf, 31 öğrenci 12.sınıftır. Tablo-1'de görüldüğü gibi araştırma katılımcılarının 214'ü (\%49.3) erkek, 208'i (\%50.7) kız öğrencilerden oluşmaktadır.

\section{Tablo 1.}

Katılımcıların Cinsiyete Göre Dağılımı

\begin{tabular}{lll}
\hline CiNSIYET & $N$ & $\%$ \\
Erkek & 214 & 49.3 \\
Kiz & 208 & 50.7 \\
Toplam & 422 & 100 \\
\hline
\end{tabular}

\section{Veri Toplama Araçları ve Süreçleri}

\section{Kişisel Bilgi Formu}

Katılımcıların yaş, cinsiyet, eğitim durumu, anne ve baba eğitim durumlarının belirlemesi amacıyla araştırmacının hazırladı̆̆ kişisel bilgi formu kullanılmıştır.

\section{Psikolojik İyi Oluş Ölçeği}

Diener ve arkadaşları tarafından geliştirilen iyi oluş ölçeğinin Türkçe diline kazandırılma çalışmaları Telef (2013) tarafından yapılmış, dil eşdeğerliliği açısından yeterli olduğu görülmüştür. Olumlu ilişkilerden 
yeterlilik hislerine, anlamlı ve amaçlı bir yaşama sahip olmaya kadar insan fonksiyonunun önemli ögelerini tanımlayan Psikolojik İyi Oluş Ölçeği sekiz maddeden oluşmaktadır. Ölçekte bütün maddelere kesinlikle katılmıyorum cevabı verildiğinde en düşük 8 puan, tüm maddelere kesinlikle katılıyorum cevabı verildiğinde en yüksek 56 puan alınabilmekte ve puanlar bu değerler arasında değişmektedir. Yüksek puan kişinin birçok psikolojik kaynak ve güce sahip olduğunu gösterir. Ölçeğin Cronbach alfa katsayıs1 .80 olarak hesaplanmıştır. Ölçeğin test-tekrar test güvenirliği farklı bölümlerde öğrenim gören 100 katılımcı üzerinde iki hafta arayla uygulanarak elde edilmiştir. Test-tekrar test güvenirliği çalışması sonucuna göre ölçeğin birinci ve ikinci uygulaması arasında yüksek düzeyde, pozitif ve anlamlı ilişki olduğu görülmüştür $(r=.86$, $p<.01)$. Ölçeğin madde toplam korelasyonlarının .41 ile .63 arasında değişiklik gösterdiği ve $\mathrm{t}$ değerlerinin anlamlı olduğu görülmektedir $(p<.001)$. Açımlayıcı faktör analizi sonucunda toplam açılanan varyansın \%42 olduğu görülmüştür. Ölçek maddelerinin faktör yükleri ise .54 ile .76 arasında hesaplanmıştır.

\section{Ergen Gelecek Beklentileri Ölçeği}

McWhirter ve McWhirter (2008) tarafından geliştirilen Bağımsız değişkenlerin ergen gelecek beklentileri üzerindeki etkisini belirlemeye dayanan Ergen Gelecek Beklentileri Ölçeği (EBGÖ) Tuncer (2011) tarafından Türkçeye uyarlanmıştır. Toplam 25 maddeden ve 4 alt boyuttan oluşan 7'li Likert tipi ölçeğin, alt boyutları 'İş ve Eğitim' (11 madde), 'Evlilik ve Aile' (7 madde), 'Din ve Toplum' (3 madde), 'Sağlık ve Yaşam' (4 madde) şeklindedir. Ölçekten en düşük 25 puan, en yüksek puan 175 alınabilmektedir. Ölçekten alınan puanların yüksek çıkması ergenlerin geleceğe ait beklentilerinin yüksek olduğu anlamı taşımaktadır. Ölçeğin Cronbach alfa iç tutarlılık katsayısı 0.92 olarak bulunmuştur. Ergen Gelecek Beklentileri Ölçeğinin geçerlilik güvenirlik çalışmaları 175 ortaöğretim öğrencisi üzerinde ilerletilmiştir. Her bir faktörün varyansa yaptığg katkıya bakıldığında birinci faktörün \%48.561, ikinci faktörün \%9,073, üçüncü faktörün \%5,416 ve dördüncü faktörün \%4,308 olduğu görülmüştür. Madde faktör yüklerinin .534 ile .896 arasında farkl1laştığ1 ortaya çıkmıştır. Bu bağlamda yapılan korelasyona göre bütün faktörler arasında pozitif ve anlamlı ilişki bulunmuştur.

\section{Sürekli Umut Ölçeği}

C.R. Snyder ve diğerleri (1991) tarafından bireyleri sürekli umut düzeyini belirlemek amacıyla geliştirilen Sürekli Umut Ölçeği on iki maddeden oluşmaktadır. Umudun Alternatif Yollar Düşüncesi ve Motivasyonel/ Eyleyici Düşünce şeklinde iki alt boyutlarına ilişkin dörder madde yer almaktadır. Bu maddelerden bir tanesi geçmişe, iki tanesi içinde bulunulan zamana ve bir tanesi de geleceğe yöneliktir. Diğer dört madde ise dolgu ifadelerinden oluşmaktadır. Likert tipi sekizli derecelendirme ölçeği kullanılmıştır. Ölçekten alınabilecek en düşük puan 8, en yüksek puan 64'dür. Ölçeğin iç tutarlılığ1 incelendiğinde Eyleyici Düşünceler bileşeninin Cronbach Alfa değerinin .71-.76, Alternatif Yollar Düşüncesi bileşeninin Cronbach Alfa değerinin .63-.80, ölçeğin toplamında Cronbach Alfa değerinin .74-.84 arasında olduğu tespit edilmiştir (Snyder vd., 1991). Ölçeğin Türkçeye ilk uyarlaması Akman ve Korkut (1993) tarafından yapılmıştır. Tarhan ve Bacanlı (2015) tarafından ölçeğin yapı ve geçerliliği açımlayıcı ve doğrulayıcı faktör analizi ile yeniden incelenmiştir. Yapılan analizler neticesinde ölçeğin Türkçe formunun orijinalindeki gibi iki faktörlü bir yapıya sahip olduğu tespit edilmiştir. İki faktörlü yapı toplam varyansın yaklaşık olarak \%61'ini açıklamaktadır. Bu çalışmada orijinal ölçekle tutarlı şekilde Alternatif Yollar ve Eyleyici Düşünce boyutlarının birbiri ile anlamlı düzeyde ilişkili olduğu, ölçeğin iç tutarlılık ve test tekrar test sonuçlarının kabul edilen sınırlar dâhilinde olduğu tespit edilmiştir

\section{Verilerin Analizi}

Araştırma, ergenlerin sahip olduğu gelecek beklentisi, umut ve psikolojik iyi oluş düzeyi arasındaki arasında 
bulunan ilişkilerin belirlenmesi ve bu değişkenler aralarındaki ilişkilerin yapısal eşitlik modeli ile sınanması amacıyla yapısal eşitlik modeli analizi yapılmıştır. Yapısal eşitlik modellemesi, kuramsal bir modeli analiz etme amacıyla gözlemlenen, değişkenler arası karşılıklı ve nedensel ilişkileri ortaya çıkaran istatistiki bir yaklaşım olarak nitelendirilebilir (Schumacker \& Lomax, 2004). Yapısal eşitlik modeli analizi AMOS 19 programı ile yapılmıştır. Araştırmada toplanan verilerin yüzde ve frekans hesapları için SPSS 18 paket programı kullanılmıştır.

\section{Etik}

Çalışmanın etik uygunluğunun tespiti için Necmettin Erbakan Üniversitesi Sosyal ve Beşeri Bilimler Bilimsel Araştırmalar Etik Kurul Başkanlığı'na başvurulmuş ve gerekli izinler alınmıştır. 15/01/2021 tarihli, 01 sayılı, 2021/21 karar numarası ile etik kurul kararınca izin alınmıştır

\section{BULGULAR (FINDINGS / RESULTS)}

Elde edilen son modelde $\left(X^{2} / s d=0.90, p<.001\right)$ dört exogenus, değerler (iş ve eğitim, evlilik ve aile, din ve toplum sağlık ve yaşam) üç endogenous (alterantif yollar düşüncesi, eyleyici düşünce ve psikolojik iyi oluş) veri bulunmaktadır. Modelde gösterilmiş olan yolların her birinin istatistiksel olarak anlamlı bulunduğu görülmüştür. TheTucker-Lewiscoefficient fit index (TLI), The Bentler-Bonettnormed fit index (NFI) ve diğer uyum indeksleri modelde oldukça iyi bir uyumluluk olduğunu göstermektedir. (Tablo-2). Modelde görülen endogenous verileri arasında iki yönlü korelasyonların her birinin yüksek değerlere sahip olduğu ve istatistiki olarak anlamlı olduğu görülmektedir. Bu anlamlı durum, değerler ölçeğinin alt boyutlarından oluşan korelasyon değerlerinden de etkilenmektedir.

\section{Tablo 2.}

Yapısal Eşitlik Modelinin Uyumuna İlişkin İstatistiksel Değerler

\begin{tabular}{llll}
\hline Ölçüm & İyi Uyum & Kabul Edilebilir Uyum & $\begin{array}{l}\text { Modelin Uyum İndeksi } \\
\text { Değerleri }\end{array}$ \\
\hline (X²/sd) & $\leq 3$ & $\leq 4-5$ & 0.90 \\
RMSEA & $\leq 0.05$ & $0.06-0.08$ & 0.02 \\
SRMR & $\leq 0.05$ & $0.06-0.08$ & 0.00 \\
NFI & $\geq 0.95$ & $0.94-0.90$ & 0.98 \\
CFI & $\geq 0.97$ & $\geq 0.95$ & 1.00 \\
GFI & $\geq 0.90$ & $0.89-0.85$ & 0.99 \\
AGFI & $\geq 0.90$ & $0.89-0.85$ & 0.98 \\
TLI & $\geq 0.95$ & $0.94-0.90$ & 1.00 \\
\hline
\end{tabular}

Tablo 2'de gösterilen uyum değerlerini incelediğimizde, $X^{2} / s d=0.90, R M S E A=0.02, S R M R=0.00, N F I$ $=0.98, C F I=1, G F I=0.99, A G F I=0.98$ ve $T L I=1.00$, olduğunu görmekteyiz. Modelin genelinde istenen düzeyde uyum değerlerinin ortaya çıktığı görülmektedir (Bollen, 1989; Byrne, 2010; Hu \& Bentler, 1999; Kline, 2011; Tanaka \& Huba, 1985). Analiz edilen tek faktörlü model Şekil 1'de gösterilmektedir. Modelde gösterilen bütün yolların 0.01 düzeyinde anlamlı olduğu görülmektedir.

Şekil 1.

Modele İlişkin Yol Analizi 


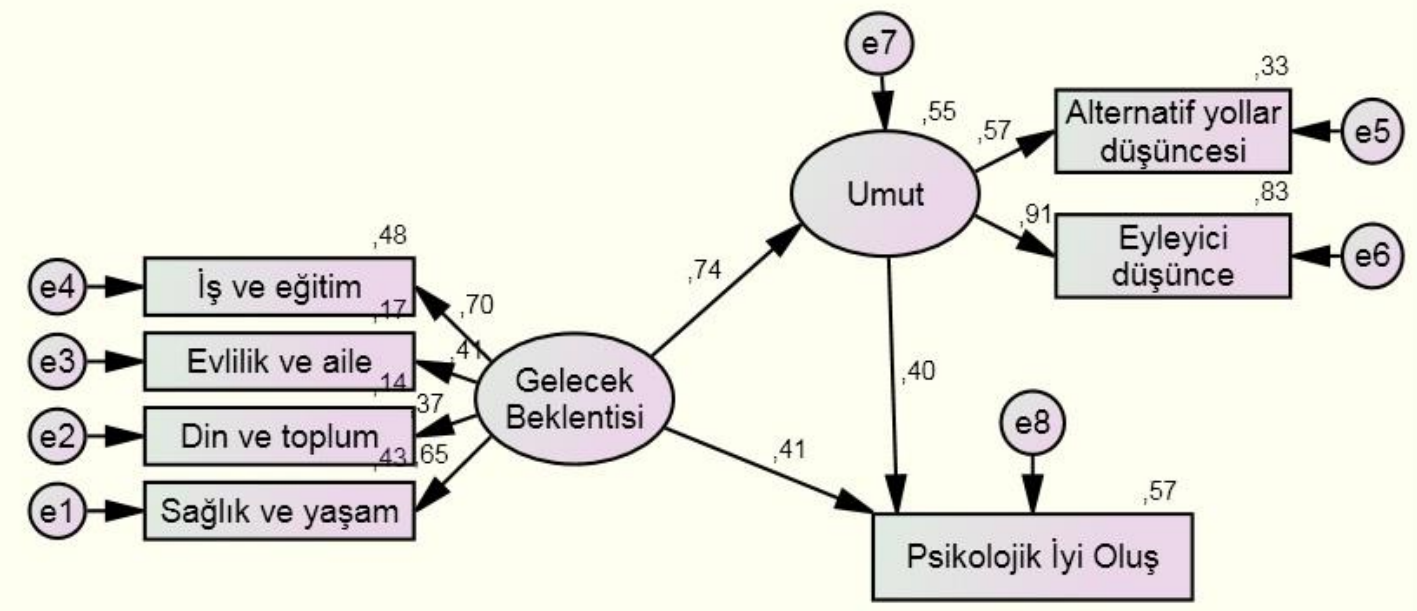

Tablo 3.

Gelecek Beklentisi ile Umut ve Psikolojik Iyi Oluş Arasındaki Yordayıcı İlişki

\begin{tabular}{lllllll}
\hline $\begin{array}{l}\text { Yordayıc1 } \\
\text { Değişken }\end{array}$ & Bağımlı Değişken & $\begin{array}{l}\text { Toplam } \\
\text { Etki }\end{array}$ & $\begin{array}{l}\text { Doğrudan } \\
\text { Etki }\end{array}$ & $\begin{array}{l}\text { Dolaylı } \\
\text { Etki }\end{array}$ & $\begin{array}{l}\text { Standart } \\
\text { Hata }\end{array}$ & $\begin{array}{l}\text { Kritik } \\
\text { Değer }\end{array}$ \\
\hline $\begin{array}{l}\text { Gelecek } \\
\text { Beklentisi }\end{array}$ & Umut & 0.74 & 0.74 & 0 & 0.07 & 7.25 \\
$\begin{array}{l}\text { Gelecek } \\
\text { Beklentisi }\end{array}$ & Psikolojik İyi Oluş & 0.70 & 0.41 & 0.29 & 0.22 & 4.08 \\
Umut & Psikolojik İyi Oluş & 0.41 & 0.40 & 0 & 0.27 & 4.31 \\
\hline
\end{tabular}

a Toplam etki $=$ Doğrudan etki + Dolaylı etki, ${ }^{*} p<0.01,{ }^{*} * p<0.05$.

Tablo 3 incelendiğinde, umudu etkileyen bağımsız değişkenin $(t=7.25, p<0.01)$ gelecek beklentisi olduğu görülmektedir. Bu faktöre dair bağlantı katsayı değeri $\beta=0.74$ olarak ortaya çıkmıştır. Tabloya göre, ergenlerin sahip oldukları gelecek beklentileri ile umutları arasındaki yordayıcı ilişkiler araştırıldığında, pozitif yönde doğrusal ve anlamlı bir ilişki tespit edilmiştir. Bir başka ifadeye göre elde edilmiş olan sonuçlar doğrultusunda, ergenlerin gelecek beklentileri arttıkça umutları da arttıracağını göstermektedir.

Modelde psikolojik iyi oluş değişkenine $(t=4.08, p<0.01)$ gelecek beklentisinin etkisi olduğu görülmüş ve bu faktöre dair bağlantı katsayı değerinin $\beta=0.41$ olduğu ortaya çıkmıştır. Ergenlerin gelecek beklentileri ile psikolojik iyi oluş düzeyleri arasındaki yordayıcı ilişkiler incelendiğinde, pozitif yönlü doğrusal ve anlamlı bir ilişkinin var olduğu görülmektedir. Bir başka ifadeye göre elde edilen sonuçlar, ergenlerin gelecek beklentileri arttıkça psikolojik iyi oluş düzeylerinin arttığını göstermektedir.

Modelde psikolojik iyi oluş değişkenine $(t=4.31, p<0.01)$ umut değişkenin etkisi olduğu görülmüş ve bu faktöre dair bağlantı katsayı değerinin $\beta=0.40$ olduğu ortaya çıkmıştır. Ergenlerin umutları ile psikolojik iyi oluş düzeyleri arasındaki yordayıcı ilişkiler incelendiğinde, pozitif yönlü doğrusal ve anlamlı bir ilişkinin var olduğu görülmektedir. Bir başka ifadeye göre elde edilen sonuçlar, ergenlerin umutları arttıkça psikolojik iyi oluş düzeylerinin arttı̆̆ını göstermektedir.

\section{TARTIŞMA / SONUÇ}


Araştırma da ergenlerin sahip oldukları gelecek beklentileri ile umutları arasındaki yordayıcı ilişkiyi incelemek amaçlanmıştır. Bu doğrultuda gerçekleştirilen çalışmada ergenlerin gelecek beklentileri arttıkça umut düzeylerinin de artacağı diğer bir deyişle gelecek beklentisinin umut düzeyinin anlamlı bir yordayıcısı olduğu ortaya çıkmıştır. Bu sonuç ergenlik döneminde okulu başarıyla bitirmek, meslek sahibi olmak, ideal bir eş bulmak, bir aileye ve mutlu bir yaşama sahip olmak gibi konularda düşünerek yaşamdan beklentilerini keşfeden genç bireylerin hedeflerine ulaşabilmesi için umut kavramının motive edici bir faktör olarak görüldügünü göstermektedir. Araştırma da elde edilen bu sonuçlar çeşitli araştırma bulgularıyla da benzerlik göstermektedir. Alanyazında olumlu gelecek yönelimine sahip bireylerin daha umutlu ve iyimser olduğu ve genel olarak iyi oluşu olumlu etkilediği bildirilmiştir (Eryılmaz 2011; Şimşek 2012; Karakoç, vd., 2013). Diğer yandan geleceğe dair beklentileri olumsuz olan bireylerin ise genel umut düzeylerinin düştüğü ortaya konulmuştur (Derman, 2013). Nitekim geleceğe dair beklentisi olumlu bireylerin daha umutlu olmas1, umut kavramı bireyin geleceğini başarıyla planlamasında anahtar bir unsur olarak tanımlanmasıyla açıklanabilir (Marsay, 2020).

Araştırma da ergenlerin gelecek beklentileri arttıkça psikolojik iyi oluş düzeylerinin de artacağı diğer bir deyişle gelecek beklentisinin psikolojik iyi oluş düzeyinin anlamlı bir yordayıcısı olduğu ortaya çıkmıştır. Mevcut çalışmanın sonuçları ergen bireylerin motivasyon, planlama ve değerlendirme aşamalarıyla geleceğe dair beklentilerini belirlemeleri onların yaşamlarındaki kendini kabul, diğerleri ile olumlu ilişkiler kurma, kişisel gelişimi destekleme, yaşam amacı bulma, çevresel egemenlik ve özerklik gibi psikolojik iyi oluş süreçlerini olumlu etkilediğine işaret etmektedir. Nitekim alanyazındaki gelişim çalışmacıları tarafından da belirtildiği gibi başarılı hedef yönetiminin psikolojik iyi oluş sürecine de katkıda bulunacağı görülmektedir (Güler-Edwards,2008). Ayrıca bireylerin geleceğe dair hedeflerini değerlendirmeleri onların gelişmelerini, kendini gerçekleştirmelerini ve yaşamlarındaki yönü belirlemelerini ortaya çıkaracağı vurgulanır (Kocayörük, vd., 2018). Mevcut çalışmada ortaya çıkan sonuçlar, çeşitli araştırma bulgularıyla da benzerlik göstermektedir. Olumlu bir gelecek beklentisine sahip olmak için iyimserliğin koruyucu bir faktör olduğu ifade edilmiştir (Sulimani-Aidan \& Benbenishty, 2011). Diğer yandan istenilen hedeflere giden yolları görebilen, bu hedeflere ulaşmak için motivasyona sahip olan bireylerin daha yüksek fiziksel ve zihinsel sağlı̆̆a sahip oldukları görülmüştür (Barnett, 2014). Gelecek beklentisinin psikolojik iyi oluşun önemli bir yordayıcısı olması değerlerini ve içsel motivasyon kaynaklarını keşfeden bireylerin hedeflerini daha belirgin hale getirmesiyle açıklanabilir. Nitekim bireylerin gelecek beklentilerini planlama süreçlerini de göz önüne aldığımızda geleceğe dair yönelimleri olumlu olan ergenlerin kendi değerlerinin ve içsel motivasyon kaynaklarının farkında olması önem kazanmaktadır. Böylece gençlerin geleceğe ilişkin beklentileri ruh sağlı̆̆ını ve psikolojik iyi oluş düzeylerini etkilediği de düşünülebilir.

Araştırmada elde edilen diğer bir bulgu neticesinde ergenlerin umut düzeyleri arttıkça psikolojik iyi oluş düzeylerinin de arttığı görülmüştür. Bu sonuç çeşitli araştırma bulgularıyla da benzerlik göstermektedir. Yapılan araştırmalarda umut ve psikolojik iyi oluş arasında tutarlı ilişkiler olduğu (Magaletta \& Oliver, 1999; Snyder vd. 2002) ve umudun psikolojik işlevsellik üzerinde önemli bir etkisi olduğu (Kashdan vd. 2002) ortaya konulmuştur. Umut ve psikolojik iyi olma arasındaki ilişkiyi inceleyen ülkemizdeki araştırmacılar da (Cenkseven-Önder \& Mukba, 2017; Kocaman, 2019) umudun psikolojik iyi olmanın önemli bir yordayıcısı olduğunu belirtmişlerdir. Mevcut araştırmanın tersine psikolojik iyi oluşun umudu yordamasıyla ilgili araştırmalarda yer almaktadır. Kardas vd. (2019) tarafından yapılan araştırmada psikolojik iyi oluşu en fazla yordayan değişkenlerin sırasıyla şükran, umut, iyimserlik ve yaşam doyumu olduğu belirlenmiştir. Sağlıklı ve mutlu bireyler olabilmek için umut düzeyinin yüksek olması ve gerçekçi umutlara sahip olmak önemli bir etkendir. Bu durum umudu yüksek bireylerin ise motivasyonel düşünceler bağlamında yaşam amacına sahip olmaları ve bu amaca ulaşmak için daha fazla yeni yöntemler üreterek davranışlarını planlamalarıyla açıklanabilir. Umut düzeyi yüksek bireylerin yaşamlarında onları amaçlarına götürecek aktiviteleri yerine getirme konusunda daha istekli olmaları ve geleceğe yönelik yüksek oranda 
kaygı yaşamamaları beklenir. Bu bağlamda hedefe ulaşmaya yönelik ürettikleri tüm yöntemler başarılı olamayınca umutlu bireyler karşılaştığı engelleri aşmak için çeşitli stratejiler üreterek, çevresel koşulları da buna göre düzenleyebilir (Snyder, 1996; vd. 2002). Dolayısıyla umut düzeyi yüksek bir birey psikolojik iyi oluş bağlamında anlamlı bir yaşam için kendini gerçekleştirebilir (Ryff \& Singer, 2008).

Araştırma bulgularına göre ergen bireylerin umudunu etkileyen önemli bağımsız değişkenin gelecek beklentisi olduğu görülmektedir. Umut ile gelecek beklentisi arasındaki pozitif, anlamlı ilişki gelecek beklentisi arttıkça umudun da artacağını göstermektedir. Diğer yandan ergenlerin psikolojik iyi oluşunu etkileyen önemli değişkenlerden birinin gelecek beklentisi olduğu sonucuna ulaşılmaktadır. Ergenlerin sahip oldukları psikolojik iyi oluş düzeyleri ile gelecek beklentisi arasında pozitif yönde anlamlı bir ilişki olduğu görülmektedir. Bu durumda ergenlerin geleceğe dair beklentileri arttıkça psikolojik iyi oluş düzeylerinin de artacağını göstermektedir. Ergenlerin psikolojik iyi oluş düzeyini etkileyen ikinci önemli değişkenin ise umut değişkeni olduğu görülmektedir. Psikolojik iyi oluş düzeyi ve umut arasındaki pozitif yönde anlamlı ilişki ergenlerin umut düzeyleri arttıkça psikolojik iyi oluş düzeylerinin de artacağını ortaya koymaktadır.

\section{ÖNERÍLER}

Bu bölümde ebeveynlere, öğretmenlere ve araştırmacılara önerilerde bulunulmuştur.

1. Öncelikle yapılan bu araştırmanın örneklemini lisede öğrenim gören (9.,10.,11.,12. Sınıf) öğrenciler oluşturmaktadır. Benzer araştırmalarım farklı örneklem grupları, farklı sosyal sistemler ile de çalışılması konu hakkında daha zengin bir alanyazın oluşmasına ve yeni görüşlerin ortaya çıkmasına imkân sağlayacaktır.

2. Bu araştırma lise öğrencilerinin oluşturduğu bir katılımcı grubundan tek seferde bilgi alınarak yapılmış kesitsel bir araştırmadır. Geçmişe yönelik ve güncel sosyal-bağlamsal faktörlerin ergenlerin gelecek beklentisi, umut ve psikolojik iyi oluşu üzerindeki etkisinin daha iyi anlaşılabilmesi için ileride yapılacak çalışmalarda boylamsal yöntemlerden yararlanılabilir.

3. Alanyazında gelecek beklentisi, umut ve psikolojik iyi oluş konusundaki çalışmaların yaygınlaştığı ve farklı disiplinlerce de çalışıldığı gözlenmiştir. Ancak belirtilen üç değişkenin birbiriyle ilişkisinin ortaya konulduğu çalışmaların oldukça sınırlı olduğu görülmüştür. Bu bağlamda gelecek beklentisi, umut ve psikolojik iyi oluşun birbiriyle ilişkisinin konu alındığı yeni çalışmaların katkısı olacağı düşünülmektedir.

4. Araştırma sonuçlarında ergenlerin geleceğe dair beklentileri arttıkça umut düzeylerinin de olumlu yönde artacağ1 görülmüştür. $\mathrm{Bu}$ bağlamda öğrencilerin kendi potansiyellerini keşfederek geleceğe dair beklentilerini daha sağlıklı planlayabilmeleri, gerçekçi ve değerlerine uygun kararlar verebilmeleri için okullarda psikolojik danışmanların önderliğinde psikoeğitim programlarının geliştirilmesi ve uygulanması faydalı olacaktır.

5. Olumsuz yaşam olaylarıyla karşılaştıklarında ergenlerin daha etkili başa çıkmalarına imkân sağlayacak umutlu düşünmeye dair programlar geliştirerek uygulanması umut seviyelerinin yükselmesine katkı sağlayacaktır. Umut düzeylerinin yükselmesi kariyer danışmanlığı noktasında ergenlerin planlama aşamalarında iyi bir başlangıç yapmalarına destek olacaktır.

6. Ek olarak ergenlerin ailelerine kendi istekleri dışında çocukların yetenek ve ilgilerini göz önüne almaları, öğretmenlerin öğrencilerin geleceğe dair hedeflerini oluşturmaları noktasında onlara nasıl yön verebilecekleri konusunda seminerler planlanarak çeşitli bilgilendirmelerin yapılmasının önemli olduğu düşünülmektedir. Böylece ailelerin ve öğretmenlerin, öğrencilerin gerçekçi hedefler belirleyerek bu hedeflere ulaşma konusunda sürekli çaba göstermeleri noktasında destek olmaları sağlanabilir.

7. Araştırma bulguları neticesinde öğrencilerin geleceğe dair beklentilerinin ve umutlarını artırıcı çalışmaların yapılması psikolojik iyi oluş düzeylerinin de artmasına katkı sağlayacaktır. Okul kültürü 
içerisinde pozitif psikolojinin yaygınlaşması, psikolojik iyi oluşun desteklenmesi için okulda görevli güvenlik personeli, temizlik çalışanı, idare ve öğretmenleri kapsayıcı pozitif psikoloji programları, hizmet içi eğitimler planlanabilir. Bu sayede öğrencilerin iyi oluşu destekleyen bir okulda eğitim almaları, onların gelişim sürecine katkı sağlayabilir.

\section{KAYNAKÇA}

Artar,M. (2003). Depremi yaşayan ergenlerin gelecek beklentilerinin içeriği. Kriz Dergisi 11(3), 21-27.

Barnett, M.D. (2014) Future Orientation and Health Among Older Adults: The Importance of Hope, Educational Gerontology, 40(10), 745-755, https://doi.org/10.1080/03601277.2014.898496

Bollen, K. A. (1989). A new incremental fit index for general structural equation models. Sociological methods \& research, 17(3), 303-316.

Büyüköztürk, Ş., Çakmak, E. K., Akgün, Ö. E., Karadeniz, Ş., \& Demirel, F. (2017). Bilimsel araştırma yöntemleri. Pegem Akademi, 1-360.

Byrne, B. M. (2010). Structural equation modeling with AMOS: basic concepts, applications, and programming (multivariate applications series). New York: Taylor \& Francis Group.

Catalano, R. F., Berglund, M. L., Ryan, J. A. M., Lonczak, H. S., \& Hawkins, J. D. (2004). Positive youth development in the United States: Research findings on evaluations of positive youth development programs. The Annuals of the American Academy of Political and Social Science, (591), 98-124.

Cenkseven-Önder, F. \& Mukba, G. (2017). Üniversite öğrencilerinde umut ve psikolojik iyi oluş arasındaki ilişkide yaşam amacının aracı rolü. The Journal Of Academic Social Science Studies, 62, 103-116.

Çelik, E. G. (2015). Algılanan ebeveyn kontrolü ile ergen iyi oluşu arasındaki ilişkide duygusal özerklik ve empatinin aracı rolü. Ankara Üniversitesi, Ankara.

Derman M.T., 2013. 10-11 Yaş Çocuklarının Saldırganlık ve Umutsuzluk Düzeyleri Arasındaki İlişkinin Belirlenmesi, The Journal Of Academic Social Science Studies, 6(2),879-889.

Erikson, E. H. (1968). Identity: Youth and crisis (No. 7). WW Norton \& company.

Givyin, K. B. (2001). Goal orientations of adolescents, coaches and parents: Is there a convergence of beliefs? Journal of early adolescence, 21(2), 228-248.

Gülaçt1, F. (2009). Sosyal beceri eğitimine yönelik programın üniversite öğrencilerinin, sosyal beceri, öznel ve psikolojik iyi olma düzeylerine etkisi. Ankara Üniversitesi, Ankara.

Güler-Edwards, A. G. (2008). Relatıonship between future tıme ortentatıon, adaptıve self-regulatıon, and wellbeing: self-type and age related differences. Orta Doğu Teknik Üniversitesi, Ankara.

Hu, L. T. \& Bentler, P. M. (1999). Cutoff criteria for fit indexes in covariance structure analysis: Conventional criteria versus new alternatives. Structural equation modeling: a multidisciplinary journal, 6(1), 1-55.

Iovu, M. B., Hărăguș, P. T. \& Roth, M. (2018) Constructing future expectations in adolescence: relation to individual characteristics and ecological assets in family and friends, International Journal of Adolescence and Youth, (23), 1-10.

Johnson, S. R. L., Blum, R. W. \& Cheng, T. L. (2014). Future orientation: A construct with implications for adolescent health and wellbeing. International journal of adolescent medicine and health, 26(4), 459468.

Karakoç, A., Bingöl, F. \& Karaca, S. (2013). Lise öğrencilerinde ergen öznel iyi oluş ile olumlu gelecek beklentisi arasındaki ilişkinin incelenmesi. Uluslararası Hakemli Akademik Spor Sağllk ve Tip Bilimleri Dergisi, 6(3), 43-50.

Karasar N. (2015). Bilimsel Araştırma Yöntemi. Ankara. Nobel Yayınevi.

Kardas, F., Cam, Z., Eskisu, M. \& Gelibolu, S. (2019). Gratitude, hope, optimism and life satisfaction as predictors of psychological well-being. Eurasian Journal of Educational Research, 82, 81-100, https://doi.org/10.14nazir689/ejer.2019.82.5. 
Kashdan, T. B., Pelham, W. E., Lang, A. R., Hoza, B., Jacob, R. G., Jennings, J. R., ... \& Gnagy, E. M. (2002). Hope and optimism as human strengths in parents of children with externalizing disorders: Stress is in the eye of the beholder. Journal of Social and Clinical Psychology, 21(4), 441-468.

Kline, R. B. (2011). Convergence of structural equation modeling and multilevel modeling.

Kocaman, E. (2019). Bir grup yetişkinde umut ve psikolojik iyi oluş arasındaki ilişsinin farkl değişkenler açısından incelenmesi. Sabahattin Zaim Üniversitesi, İstanbul.

Kocayörük, E., Altıntaş, E., Şimşek, Ö., Bozanoğlu, İ. \& Çelik, B. (2018). Üniversite öğrencilerinin zaman perspektifli iyi oluş düzeyleri-kümeleme analizi incelemesi. Hacettepe Üniversitesi Eğitim Fakültesi Dergisi (H. U. Journal of Education) 33(3), 550-564.

Magaletta, P. R. \& Oliver, J. M. (1999). The hope construct, will and ways: Their relations with self-efficacy, optimism and general well-being. Journal of Clinical Psychology, 55, 539-551.

Marsay, G. (2020). A hope-based future orientation intervention to arrest adversity. South African Journal of Education, 40(1).

Masten, A.S. \& Coatsworth, J.D. (1998). The development of competence in favorable and unfavorable environments: Lessons from research on successful children. American psychologist, 53(2), 205.

McCabe, K. \& Barnett D. (2000). First comes work, then comes marriage: Future orientation among, African American young adolescents. Family Relations. (49), 63-70.

Nurmi, J. E. (1991). How do adolescents see their future? A review of the development of futureorientation and planning. Developmental Review, (2), 1-59.

Roberts, R. E. \& Bengtson, V. L. (1993). Relationships with parents, self-esteem, and psychological well-being in young adulthood. Social psychology quarterly, 263-277.

Rotter, J. B. (1975). Some problems and misconceptions related to the construct of internal versus external control of reinforcement. Journal of Consulting and Clinical Psychology, 43(1), 56-67.

Ryff, C. D. \& Singer, B. H (2008). Know Thyself and Become What You Are A Eudaimonic Approach to Psychological Well-Being. Journal of Happiness Studies. (9), 13-39.

Ryff, C. D. (1989). Happiness is Everything, or is It Explorations on the Meaning of Psychological Well-Being. Journal of Personality and Social Psychology, (57),1069-1081.

Ryff, C. D. (2013). Psychological well-being revisited, Advances in the science and practice of eudaimonia. Psychother Psychosom (83), 10-28.

Santrock, J. W (2012). Yaşam boyu gelişim. (352-353) (13.baskıdan çeviri) Ankara: Nobel Yayınları.

Schumacker, R. E. \& Lomax, R. G. (2004). A beginner's guide to structural equation modeling. Psychology press.

Seginer, R. (2003). Adolescent future orientation: An integrated cultural and ecological perspective. Online Readings in Psychology and Culture, 6(1).

Snyder, C. R, Rand, K. L., King, E. A., Feldman, D. B. \& Woodward, J. T. (2002). False 'hope'. Journal of Clinical Psychology, 58(9), 1003-1022.

Snyder, C. R. (1995). Conceptualizing, measuring and nurturing hope. Journal of Counseling, Development, 73(1), 355-360.

Snyder, C. R. (1996). To hope, to lose, and to hope again, Journal of Personal and Interpersonal Loss: International Perspectives on Stress \& Coping, 1(1), 1-16.

Snyder, C. R. (2000). The past and possible futures of hope. Journal of Social and Clinical Psvchologv, 19(1) 1128.

Snyder, C. R. (2002). Target Article: Hope theory: rainbows in the mind, Psychological Inquiry, (13:4), 249-275.

Sulimani-Aidan, Y. \& Benbenishty, R. (2011). Future expectations of adolescents in residential care in Israel. Children and Youth Services Review, 33(7), 1134-1141.

Sürücü, A. \& Mutlu, D. (2016). Bireyin yaşamında umut. (Ed. N. Sargın, S. Avşaroğlu, A. Ünal), Eğitimden Psikolojik Yansimalar, (s. 115-124) içinde. Konya: Çizgi Kitabevi.

Şimşek, H., (2012). “Güney Doğu Anadolu bölgesindeki lise öğrencilerinin gelecek beklentileri ve gelecek beklentilerini etkileyen faktörler”, Kurumsal Eğitim Bilimleri Dergisi, 5(1), 90-109. 
Tanaka, J. S. \& Huba, G. J. (1985). A fit index for covariance structure models under arbitrary GLS estimation. British journal of mathematical and statistical psychology, 38(2), 197-201.

Tarhan, S. \& Bacanlı, H. (2015). Sürekli umut ölçeğinin Türkçe’ye uyarlanması: Geçerlilik ve güvenirlik çalışmasi. The Journal of Happiness and Well-Being, 3(1), 1-14

Telef, B. B. (2013). Psikolojik İyi Oluş Ölçeği: Türkçeye uyarlama, geçerlik ve güvenirlik çalışması. Hacettepe Üniversitesi Eğitim Fakültesi Dergisi 28(3), 374-384.

Tuncer, M. (2011) Ergen gelecek beklentileri ölçeğinin Türkçeye uyarlanmas1. Turkish Studies - International Periodical For The Languages, Literature and History of Turkish or Turkic, 6(3), 1265-1275.

Türkon, H. (2019). Ergenlerde (14-18) bağlanma stilleri ile gelecek beklentisi ve öz-denetim arasindaki ilişkinin incelenmesi: Kayseri örneği. Çağ Üniversitesi, Mersin.

Valero, D., Hirschi, A. \& Strauss, K. (2015). Hope in Adolescent Careers: Mediating Effects of Work Motivation on Career Outcomes in Swiss Apprentices. Journal of Career Development, 42, 381-395.

\section{EXTENDED ABSTRACT}

Introduction: It is considered important for individuals in adolescence, who experience significant changes in various dimensions of personality development, to determine their future goals and to make an effort to reach these goals with hope. Therefore, determining psychological well-being and hope levels, especially in high school students in adolescence, which is an important stage of life, will make efforts to increase well-being levels more effective. On the other hand, when the situations of individuals with negative future expectations are evaluated, it is important to determine the factors associated with future expectations in adolescents and to carry out studies on these factors. From this point of view, the general purpose of the research is to reveal the predictive relationships between adolescents' future expectation, hope and psychological well-being levels.

Materials and Methods: In this study conducted with quantitative research paradigm, it is aimed to determine the relationships between the future expectation, hope and psychological well-being of adolescents and to test the relationships of these variables with the structural equation model. The research for this purpose was based on the relational scanning model, which is a sub-dimension of the general scanning model. The working group of the research consists of students who are studying in the 9.10.11.12th grades of Science, Anatolian and Vocational High Schools of Turkey's private and public schools in the 2019-2020 academic year. The research working group consists of students between the ages of 14 and 18 .

Findings: In the final model,we obtained $\left(X^{2} / s d=0.90, p<.001\right)$ four exogenus, values (work and education, marriage and family, religion and society, health and life) and three endogenous (thought of alternative ways, acting thinking and psychological well-being) data exists. Each of the paths shown in the model was found to be statistically significant. TheTucker-Lewiscoefficient fit index (TLI), The Bentler-Bonettnormed fit index (NFI) and other fit indexes show a very good fit in the model. It is seen that each of the two-way correlations between the endogenous data seen in the model has high values and is statistically significant. This significant situation is also affected by the correlation values consisting of the sub-dimensions of the values scale. When we examine the fit values, we see that $X^{2} / s d=0.90, R M S E A=0.02, S R M R=0.00, N F I=0.98, C F I=1, G F I=0.99, A G F I=0.98$ and $T L I=1.00$. It is seen that the desired level of fit values emerge throughout the model (Bollen, 1989; Byrne, 2010; Hu \& Bentler, 1999; Kline, 2011; Tanaka \& Huba, 1985). It is seen that the independent variable $(t=7.25$, $p<0.01)$ affecting hope is future expectation. The correlation coefficient value for this factor turned out to $b e \beta=$ 0.74 . According to the table, when the predictive relationships between adolescents' future expectations and hopes were investigated, a positive linear and significant relationship was found. In other words, in line with the results obtained, it shows that as adolescents' future expectations increase, their hopes will also increase. In the model, it was observed that the variable $(t=4.08, p<0.01)$ affecting the psychological well-being variable was future expectation, and the correlation coefficient value for this factor was found to be $\beta=0.41$. When the predictive relationships between the future expectations of adolescents and their psychological well-being levels are examined, it is seen that there is a positive linear and significant relationship. In other words, the results obtained show that as adolescents' future expectations increase, their psychological well-being levels increase. In the model, it was observed that the variable affecting the psychological well-being variable $(t=4.31, p<0.01)$ was the hope variable, and the correlation coefficient value for this factor was found to be $\beta=0.40$. When the 
predictive relationships between adolescents' hopes and psychological well-being levels are examined, it is seen that there is a positive linear and significant relationship. In other words, the results obtained show that as adolescents' hopes increase, their psychological well-being levels increase.

Discussion: In the study, it was found that as adolescents' expectations of the future increase, their level of hope will increase, in other words, the level of hope of the future is a meaningful reliever. This result shows that the concept of hope is seen as a motivating factor for young individuals who discover their expectations from life by thinking about issues such as successfully finishing school during adolescence, having a profession, finding an ideal partner, having a family and a happy life. On the other hand, it has been revealed that the psychological well-being levels of adolescents will increase as their future expectations increase, in other words, the level of psychological wellbeing of the future expectation is a meaningful fatigue. The results of the current study indicate that the determination of adolescent individuals' expectations for the future through motivation, planning and evaluation stages positively affects psychological well-being processes such as self-acceptance in their lives, building positive relationships with others, supporting personal development, finding a life goal, environmental sovereignty and autonomy. As a result of another finding obtained in the study, it was seen that the psychological well-being levels of adolescents increased as their hope levels increased. In order to be healthy and happy individuals, high level of hope and having realistic hopes is an important factor. This can be explained by the fact that highly hopeful individuals have a life goal in the context of motivational thoughts and plan their behavior by creating more new methods to achieve this goal. 